\title{
Developing a Diagnostic Bundle for Bronchiectasis in South Korea: A Modified Delphi Consensus Study
}

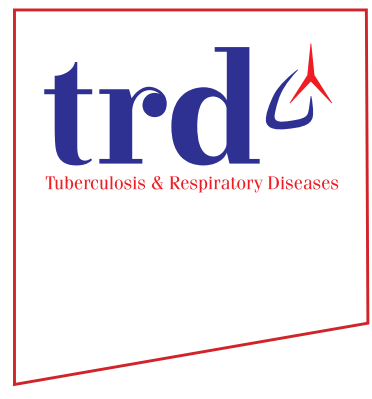

Hayoung Choi, M.D., Ph.D. ${ }^{1}{ }^{(\mathbb{0},}$, Hyun Lee, M.D., Ph.D. ${ }^{2}$, Seung Won Ra, M.D., Ph.D. ${ }^{3}$, Jong Geol Jang, M.D. ${ }^{4}$, Ji-Ho Lee, M.D., Ph.D. ${ }^{5}$, Byung Woo Jhun, M.D., Ph.D. ${ }^{6}$, Hye Yun Park, M.D., Ph.D. ${ }^{6}$, Ji Ye Jung, M.D., Ph.D. ${ }^{7}$, Seung Jun Lee, M.D., Ph.D. ${ }^{8}$, Kyung-Wook Jo, M.D., Ph.D. ${ }^{9}$, Chin Kook Rhee, M.D., Ph.D. ${ }^{10}$, Changwhan Kim, M.D., Ph.D. ${ }^{11}$, Sei Won Lee, M.D., Ph.D. ${ }^{9}$, Kyung Hoon Min, M.D., Ph.D. ${ }^{12}$, Yong-Soo Kwon, M.D., Ph.D. ${ }^{13}$, Deog Kyeom Kim, M.D., Ph.D. ${ }^{14}$, Jin Hwa Lee, M.D., Ph.D. ${ }^{15}$, Yong Bum Park, M.D., Ph.D. ${ }^{16}$, Eun Hee Chung, M.D., Ph.D. ${ }^{17}$, Yae-Jean Kim, M.D., Ph.D. ${ }^{18}$, Kwang Ha Yoo, M.D., Ph.D. ${ }^{19}$ and Yeon-Mok Oh, M.D., Ph.D. ${ }^{9}$ (iD

*Author affiliations appear at the end of this article.

Background: Because the etiologies of bronchiectasis and related diseases vary significantly among different regions and ethnicities, this study aimed to develop a diagnostic bundle for bronchiectasis in South Korea.

Methods: A modified Delphi method was used to develop expert consensus statements on a diagnostic bundle for bronchiectasis in South Korea. Initial statements proposed by a core panel, based on international bronchiectasis guidelines, were discussed in an online meeting and two email surveys by a panel of experts ( $\geq 70 \%$ agreement).

Results: The study involved 21 expert participants, and 30 statements regarding a diagnostic bundle for bronchiectasis were classified as recommended, conditional, or not recommended. The consensus statements of the expert panel were as follows: A standardized diagnostic bundle is useful in clinical practice; diagnostic tests for specific diseases, including immunodeficiency and allergic bronchopulmonary aspergillosis, are necessary when clinically suspected; initial diagnostic tests, including sputum microbiology and spirometry, are essential in all patients with bronchiectasis, and patients suspected with rare causes such as primary ciliary dyskinesia should be referred to specialized centers.

Conclusion: Based on this Delphi survey, expert consensus statements were generated including specific diagnostic, laboratory, microbiological, and pulmonary function tests required to manage patients with bronchiectasis in South Korea.

Keywords: Bronchiectasis; Diagnosis; Consensus Guideline; Korea; Survey

Address for correspondence: Yeon-Mok Oh, M.D., Ph.D.

Department of Pulmonary and Critical Care Medicine, Asan Medical Center, University of Ulsan College of Medicine, 88 Olympic-ro 43-gil, Songpa-gu, Seoul 05505, Republic of Korea

Phone: 82-2-3010-3136, Fax:82-2-3010-6968, E-mail: ymoh55@amc.seoul.kr, yeonmok.oh@gmail.com

Received: Sep. 8, 2021, Revised: Oct. 19, 2021, Accepted: Nov. 7, 2021, Published online: Nov. 15, 2021

@(c) it is identical to the Creative Commons Attribution Non-Commercial License (http://creativecommons.org/licenses/by-nc/4.0/) 


\section{Introduction}

Bronchiectasis is a chronic respiratory disease characterized by abnormal dilatation of the bronchi, with clinical manifestations of cough, sputum, and recurrent infection ${ }^{1,2}$. The prevalence and disease burden of bronchiectasis has increased worldwide ${ }^{3-6}$, including South Korea ${ }^{1,7-9}$. One of the obstacles to adequately addressing the disease burden of bronchiectasis is its heterogeneity ${ }^{10,11}$, as it may be caused by or related to various respiratory or systemic diseases ${ }^{12,13}$.

Given the heterogeneity of the disease, a systematic etiologic evaluation is recommended by various international bronchiectasis guidelines ${ }^{14,15}$. Determining the etiology is of paramount importance in order to prescribe appropriate treatment and improve patients' outcomes ${ }^{16,17}$. The interna- tional bronchiectasis guidelines, which suggest a minimum diagnostic bundle as part of the systematic approach, play a crucial role in the management of patients with bronchiecta$\mathrm{sis}^{15}$. However, there are significant differences in the etiology and comorbidities of bronchiectasis among different countries and regions ${ }^{10}$.

It may be inappropriate to apply the diagnostic bundles suggested by other international societies without modification for the management of patients with bronchiectasis in South Korea. This study developed a diagnostic bundle for patients with bronchiectasis in South Korea.

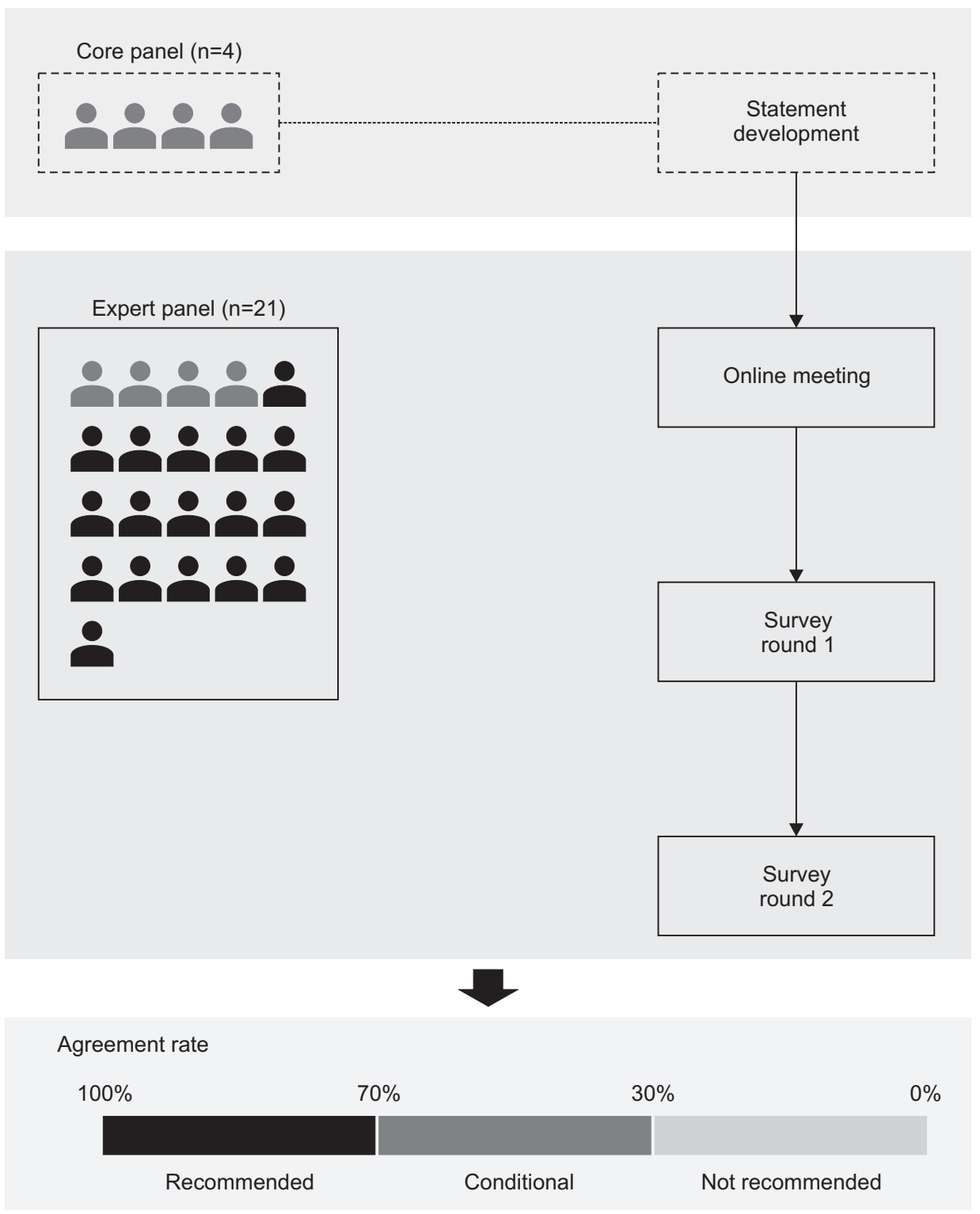

Figure 1. Flowchart of a modified Delphi method. 
Table 1. Survey round 1: questions and agreement/disagreement rates

\begin{tabular}{|c|c|c|}
\hline & $\begin{array}{l}\text { Choose one of the answers to each statement } \\
\text { (Strongly agree/Agree/Neutral/Disagree/Strongly disagree) }\end{array}$ & $\begin{array}{c}\text { Agreement/Neutral/ } \\
\text { Disagreement rates }(\%)^{*}\end{array}$ \\
\hline \multicolumn{3}{|c|}{ Section 1. Overview } \\
\hline Q1 & A standardized diagnostic bundle for bronchiectasis is useful in clinical practice. & $95 / 5 / 0$ \\
\hline Q2 & $\begin{array}{l}\text { In patients }<50 \text { years of age without a definite cause of bronchiectasis, additional tests should } \\
\text { be performed to elucidate the etiology. Additional testing for primary ciliary dyskinesia, cystic } \\
\text { fibrosis, alpha } 1 \text { antitrypsin deficiency, and immunoglobulin deficiency may be performed. }\end{array}$ & $80 / 15 / 5$ \\
\hline \multicolumn{3}{|c|}{ Section 2. Tests to search for the causes of bronchiectasis } \\
\hline Q3 & All patients should receive a chest CT when first diagnosed with bronchiectasis. & $95 / 5 / 0$ \\
\hline Q4 & $\begin{array}{l}\text { All patients should receive tests related to ABPA such as CBC, total Ig E, specific Ig E, or skin test } \\
\text { for Aspergillus fumigatus. }\end{array}$ & $35 / 25 / 40$ \\
\hline Q5 & $\begin{array}{l}\text { Tests related to ABPA should be performed only in patients with bronchiectasis carrying a history } \\
\text { of asthma. }\end{array}$ & $60 / 5 / 35$ \\
\hline Q6 & $\begin{array}{l}\text { Serum Ig levels (Ig G, Ig A, and Ig M) should be measured in all patients when first diagnosed } \\
\text { with bronchiectasis. }\end{array}$ & $40 / 30 / 30$ \\
\hline Q7 & $\begin{array}{l}\text { Serum Ig levels (B cell immunity) should be measured only when immunodeficiency (e.g., } \\
\text { recurrent infections) is suspected. }\end{array}$ & $60 / 10 / 30$ \\
\hline Q8 & $\begin{array}{l}\text { A baseline level of antibody specific to Streptococcus pneumoniae capsular polysaccharides } \\
\text { should be measured in all patients when first diagnosed with bronchiectasis. }\end{array}$ & $20 / 20 / 60$ \\
\hline Q9 & $\begin{array}{l}\text { If the baseline level of specific antibody to } S \text {. pneumoniae capsular polysaccharides is low, it } \\
\text { should be remeasured } 4-8 \text { weeks after pneumococcal } 23 \text { polyvalent vaccine injection. }\end{array}$ & $30 / 35 / 35$ \\
\hline Q10 & $\begin{array}{l}\text { A baseline level of antibody specific to } S \text {. pneumoniae capsular polysaccharides should be } \\
\text { measured only when immunodeficiency is suspected. }\end{array}$ & $65 / 35 / 0$ \\
\hline Q11 & $\begin{array}{l}\text { Repetitive measurement of antibody specific to } S \text {. pneumoniae capsular polysaccharides should } \\
\text { be performed } 4-8 \text { weeks after pneumococcal } 23 \text { polyvalent vaccine injection only when } \\
\text { immunodeficiency is suspected and the baseline level is low. }\end{array}$ & $60 / 30 / 10$ \\
\hline Q12 & $\begin{array}{l}\text { Autoimmune markers (FANA, RF, anti-CCP, ANCA) should be measured in all patients when first } \\
\text { diagnosed with bronchiectasis. }\end{array}$ & $40 / 25 / 35$ \\
\hline Q13 & Autoimmune markers should be measured only when rheumatologic diseases are suspected. & $65 / 15 / 20$ \\
\hline Q14 & $\begin{array}{l}\text { When primary ciliary dyskinesia is suspected, clinicians should refer patients to institutions } \\
\text { where diagnostic tests are available. }\end{array}$ & $100 / 0 / 0$ \\
\hline Q15 & $\begin{array}{l}\text { In patients }<50 \text { years of age without a definite cause of bronchiectasis, questionnaires of high } \\
\text { diagnostic sensitivity should be used for the differential diagnosis of primary ciliary dyskinesia. }\end{array}$ & $85 / 15 / 0$ \\
\hline Q16 & $\begin{array}{l}\text { When alpha- } 1 \text { antitrypsin deficiency is suspected, clinicians should refer patients to institutions } \\
\text { where diagnostic tests are available. }\end{array}$ & $95 / 5 / 0$ \\
\hline Q17 & $\begin{array}{l}\text { If patients }<50 \text { years of age without a definite cause of bronchiectasis and demonstrate panacinar } \\
\text { emphysema on basal lung CXR, tests for alpha- } 1 \text { antitrypsin deficiency should be performed. }\end{array}$ & $60 / 35 / 5$ \\
\hline Q18 & $\begin{array}{l}\text { When cystic fibrosis is suspected, clinicians should refer patients to institutions where diagnostic } \\
\text { tests are available. }\end{array}$ & $90 / 10 / 0$ \\
\hline \multicolumn{3}{|c|}{ Section 3. Pulmonary function and microbiological tests } \\
\hline Q19 & $\begin{array}{l}\text { Prebronchodilator spirometry should be performed in all patients when first diagnosed with } \\
\text { bronchiectasis. }\end{array}$ & $100 / 0 / 0$ \\
\hline Q20 & $\begin{array}{l}\text { Postbronchodilator spirometry combined with prebronchodilator spirometry is indicated for all } \\
\text { patients first diagnosed with bronchiectasis. }\end{array}$ & $95 / 0 / 5$ \\
\hline Q21 & Diffusion capacity should be measured if indicated when first diagnosed with bronchiectasis. & $65 / 25 / 10$ \\
\hline Q22 & Lung volume should be measured if indicated when first diagnosed with bronchiectasis. & $40 / 40 / 20$ \\
\hline Q23 & $\begin{array}{l}\text { Sputum Gram stain and bacterial culture should be performed in all patients when first } \\
\text { diagnosed with bronchiectasis. }\end{array}$ & $90 / 5 / 5$ \\
\hline
\end{tabular}


Table 1. Continued

\begin{tabular}{|c|c|c|}
\hline \multicolumn{2}{|r|}{$\begin{array}{l}\text { Choose one of the answers to each statement } \\
\text { (Strongly agree/Agree/Neutral/Disagree/Strongly disagree) }\end{array}$} & $\begin{array}{c}\text { Agreement/Neutral/ } \\
\text { Disagreement rates }(\%)^{*}\end{array}$ \\
\hline Q24 & $\begin{array}{l}\text { Sputum AFB stain and culture should be performed in all patients when first diagnosed with } \\
\text { bronchiectasis. }\end{array}$ & $95 / 5 / 5$ \\
\hline Q25 & $\begin{array}{l}\text { Sputum fungal culture should be performed in all patients when first diagnosed with } \\
\text { bronchiectasis. }\end{array}$ & $50 / 25 / 25$ \\
\hline Q26 & $\begin{array}{l}\text { All patients should receive testing for chronic pulmonary aspergillosis when first diagnosed with } \\
\text { bronchiectasis. }\end{array}$ & $0 / 45 / 55$ \\
\hline Q27 & $\begin{array}{l}\text { Tests for chronic pulmonary aspergillosis should be performed when patients with } \\
\text { bronchiectasis manifest chronic pulmonary disease and chronic pulmonary aspergillosis is } \\
\text { suspected. }\end{array}$ & $95 / 5 / 0$ \\
\hline \multicolumn{3}{|c|}{ Section 4. Laboratory tests } \\
\hline Q28 & $\begin{array}{l}\text { All stable patients should receive laboratory testing, including } \mathrm{CBC} \text {, liver function tests, BUN, } \\
\text { creatinine, and CRP. }\end{array}$ & $95 / 5 / 0$ \\
\hline Q30 & All patients should receive PNS CT when first diagnosed with bronchiectasis. & $5 / 15 / 80$ \\
\hline \multicolumn{3}{|c|}{ Optimal cutoff for analyzing survey results } \\
\hline Q31 & $\begin{array}{l}\text { What is the optimal cutoff for analyzing survey results? } \\
\text { (A } 70 \% / 30 \% \text { cutoff means a statement with } \geq 70 \% \text { agreement should be recommended, a } \\
\text { statement with } \geq 30 \% \text { and }<70 \% \text { agreement rate should be considered as conditional based on } \\
\text { the choice of the physician and patient, and a statement with }<30 \% \text { agreement should not be } \\
\text { recommended.) } \\
\text { A) } 70 \% / 30 \% \text {, B) } 80 \% / 30 \% \text {, C) } 70 \% / 20 \% \text {, D) } 80 \% / 20 \%\end{array}$ & $\begin{array}{l}\text { A) } 71 \\
\text { B) } 12 \\
\text { C) } 6 \\
\text { D) } 12\end{array}$ \\
\hline
\end{tabular}

*Agreement rate was defined as the percentage of experts who answered, "strongly agree" or "agree," and the disagreement rate was the percentage who answered "disagree" or "strongly disagree."

CT: computed tomography; ABPA: allergic bronchopulmonary aspergillosis; CBC: complete blood count; FANA: fluorescent antinuclear antibody; RF: rheumatoid factor; anti-CCP: anti-cyclic citrullinated peptide; ANCA: antineutrophil cytoplasmic antibodies; CXR: chest X-ray; BUN: blood urea nitrogen; CRP: C-reactive protein; PNS: paranasal sinus.

\section{Materials and Methods}

\section{Study design}

This study incorporated a two-step, modified Delphi method ${ }^{18}$ focusing on developing a diagnostic bundle for bronchiectasis in South Korea. The Delphi method is recommended for use in the healthcare setting as a reliable means of determining consensus for a defined clinical problem ${ }^{19,20}$. Initially, a comprehensive list of items was identified, and a set of statements was proposed by four core panelists (HC, HL, SWR, and YMO) based on recently published international guidelines for bronchiectasis ${ }^{14,15}$. The draft document containing the list of statements was circulated by email to all panel members. Subsequently, an online meeting (March 8, 2021) attended by an expert panel (see below) was held before initiation of two rounds of Delphi surveys. During the process, a set of statements was modified and updated based on the expert panel's feedback (Figure 1). The study protocol was approved by the Institutional Review Board of Asan Medical
Center (application no. 2021-0218). All 21 participants provided informed consent and received written information about the study.

\section{Panel selection}

Panel members were selected from study groups of the Korean Academy of Tuberculosis and Respiratory Diseases, the official Korean society of respiratory physicians, based on their clinical and research expertise in the diagnosis and treatment of bronchiectasis. Twenty-one experts were initially contacted and asked to participate in consensus development. Among the 21 expert panels, 20 experts were selected from three study groups of the Korean Academy of Tuberculosis and Respiratory Diseases: 16 from the Bronchiectasis Study Group (four of the 16 were the core panel members), two from the Chronic Obstructive Pulmonary Disease Study Group, and two from the Tuberculosis Study Group. Additionally, one pediatrician, who is an expert in the field of primary ciliary dyskinesia, was also included in the expert panel. The 
Table 2. Survey round 2: questions and agreement/disagreement rates

\begin{tabular}{|c|c|c|}
\hline & $\begin{array}{l}\text { Choose one of the answers to each statement } \\
\text { (Strongly agree/Agree/Neutral/Disagree/Strongly disagree) }\end{array}$ & $\begin{array}{l}\text { Agreement/Neutral/ } \\
\text { Disagreement rates }(\%)^{*}\end{array}$ \\
\hline \multicolumn{3}{|c|}{ Section 1. Overview } \\
\hline Q1 & A standardized diagnostic bundle for bronchiectasis is useful in clinical practice. & $100 / 0 / 0$ \\
\hline Q2 & $\begin{array}{l}\text { In patients }<50 \text { years of age without definite cause of bronchiectasis, additional tests should be } \\
\text { performed to elucidate the etiology beyond a specific diagnostic bundle. }\end{array}$ & $80 / 20 / 0$ \\
\hline \multicolumn{3}{|c|}{ Section 2 . Tests to search for the causes of bronchiectasis } \\
\hline Q3 & All patients should receive a chest CT when first diagnosed with bronchiectasis. & $95 / 5 / 0$ \\
\hline Q4 & $\begin{array}{l}\text { All patients should receive tests to elucidate eosinophilic endotype (CBC, total Ig E) when first } \\
\text { diagnosed with bronchiectasis. }\end{array}$ & $55 / 15 / 30$ \\
\hline Q5 & All patients should receive tests related to ABPA when first diagnosed with bronchiectasis. & $15 / 30 / 55$ \\
\hline Q6 & $\begin{array}{l}\text { Tests related to ABPA should be performed only in patients with bronchiectasis carrying a history } \\
\text { of asthma. }\end{array}$ & $80 / 5 / 15$ \\
\hline Q7 & $\begin{array}{l}\text { Serum Ig levels should be measured in patients }<50 \text { years of age when first diagnosed with } \\
\text { bronchiectasis. }\end{array}$ & $65 / 15 / 20$ \\
\hline Q8 & Serum Ig levels should be measured only when immunodeficiency is suspected. & $70 / 5 / 25$ \\
\hline Q9 & $\begin{array}{l}\text { A baseline level of antibody specific to Streptococcus pneumoniae capsular polysaccharides } \\
\text { should be measured in all patients when first diagnosed with bronchiectasis. }\end{array}$ & $0 / 15 / 85$ \\
\hline Q10 & $\begin{array}{l}\text { A baseline level of antibody specific to } S \text {. pneumoniae capsular polysaccharides should be } \\
\text { measured only when immunodeficiency is suspected. }\end{array}$ & $90 / 10 / 0$ \\
\hline Q11 & $\begin{array}{l}\text { Repetitive measurement of antibody levels specific to } S \text {. pneumoniae capsular polysaccharides } \\
\text { should be performed } 4-8 \text { weeks after pneumococcal } 23 \text { polyvalent vaccine injection only when } \\
\text { immunodeficiency is suspected and the baseline level was low. }\end{array}$ & $85 / 15 / 0$ \\
\hline Q12 & $\begin{array}{l}\text { Autoimmune markers should be measured in patients }<50 \text { years of age when first diagnosed with } \\
\text { bronchiectasis. }\end{array}$ & $50 / 25 / 25$ \\
\hline Q13 & Autoimmune markers should be measured only when rheumatologic diseases are suspected. & $95 / 5 / 0$ \\
\hline Q14 & $\begin{array}{l}\text { When primary ciliary dyskinesia is suspected, clinicians should refer patients to institutions where } \\
\text { diagnostic tests are available. }\end{array}$ & $100 / 0 / 0$ \\
\hline Q15 & $\begin{array}{l}\text { In patients }<50 \text { years of age without a definitive cause of bronchiectasis, questionnaires with a high } \\
\text { diagnostic sensitivity should be used for the differential diagnosis of primary ciliary dyskinesia. }\end{array}$ & $100 / 0 / 0$ \\
\hline Q16 & $\begin{array}{l}\text { When alpha-1 antitrypsin deficiency is suspected, clinicians should refer patients to institutions } \\
\text { where diagnostic tests are available. }\end{array}$ & $100 / 0 / 0$ \\
\hline Q17 & $\begin{array}{l}\text { If patients }<50 \text { years of age do not have a definitive cause of bronchiectasis and demonstrate } \\
\text { panacinar emphysema on basal lung CXR, tests for alpha-1 antitrypsin deficiency should be } \\
\text { performed. }\end{array}$ & $80 / 20 / 0$ \\
\hline Q18 & $\begin{array}{l}\text { When cystic fibrosis is suspected, clinicians should refer patients to institutions where diagnostic } \\
\text { tests are available. }\end{array}$ & $100 / 0 / 0$ \\
\hline \multicolumn{3}{|c|}{ Section 3. Pulmonary function and microbiological tests } \\
\hline Q19 & $\begin{array}{l}\text { Prebronchodilator spirometry should be performed in all patients when first diagnosed with } \\
\text { bronchiectasis. }\end{array}$ & $100 / 0 / 0$ \\
\hline Q20 & $\begin{array}{l}\text { Postbronchodilator spirometry should be performed in all patients when first diagnosed with } \\
\text { bronchiectasis. }\end{array}$ & $100 / 0 / 0$ \\
\hline Q21 & Diffusion capacity should be included in a diagnostic bundle for bronchiectasis. & $45 / 25 / 30$ \\
\hline Q22 & Lung volume should be included in a diagnostic bundle for bronchiectasis. & $35 / 20 / 45$ \\
\hline Q23 & $\begin{array}{l}\text { Sputum Gram stain and bacterial culture should be performed in all patients when first diagnosed } \\
\text { with bronchiectasis. }\end{array}$ & $95 / 0 / 5$ \\
\hline Q24 & $\begin{array}{l}\text { Sputum AFB stain and culture should be performed in all patients when first diagnosed with } \\
\text { bronchiectasis. }\end{array}$ & $95 / 0 / 5$ \\
\hline
\end{tabular}


Table 2. Cotinued

\begin{tabular}{|c|c|c|}
\hline \multicolumn{2}{|r|}{$\begin{array}{l}\text { Choose one of the answers to each statement. } \\
\text { (Strongly agree/Agree/Neutral/Disagree/Strongly disagree) }\end{array}$} & $\begin{array}{c}\text { Agreement/Neutral/ } \\
\text { Disagreement rates }(\%)^{*}\end{array}$ \\
\hline Q25 & $\begin{array}{l}\text { Sputum fungal culture should be performed in all patients when first diagnosed with } \\
\text { bronchiectasis. }\end{array}$ & $25 / 35 / 40$ \\
\hline Q26 & $\begin{array}{l}\text { All patients should be tested for chronic pulmonary aspergillosis when first diagnosed with } \\
\text { bronchiectasis. }\end{array}$ & $5 / 15 / 80$ \\
\hline Q27 & $\begin{array}{l}\text { Tests for chronic pulmonary aspergillosis should be performed only when chronic pulmonary } \\
\text { aspergillosis is suspected. }\end{array}$ & $95 / 5 / 0$ \\
\hline \multicolumn{3}{|c|}{ Section 4. Laboratory tests } \\
\hline Q28 & $\begin{array}{l}\text { All patients should undergo laboratory testing, including CBC, liver function, BUN, creatinine, and } \\
\text { CRP, when they are in a stable state. }\end{array}$ & $95 / 0 / 5$ \\
\hline \multicolumn{3}{|c|}{ Section 5. Paranasal sinus tests } \\
\hline Q29 & All patients should receive a PNS X-ray when first diagnosed with bronchiectasis. & $90 / 5 / 5$ \\
\hline
\end{tabular}

*Agreement rate was defined as the percentage of experts who answered "strongly agree" or "agree." The disagreement rate was the percentage of experts who answered "disagree" or "strongly disagree."

CT: computed tomography; CBC: complete blood count; ABPA: allergic bronchopulmonary aspergillosis; CXR: chest X-ray; BUN: blood urea nitrogen; PNS: paranasal sinus.

other pediatrician, who is an expert in the field of primary immunodeficiency, served as a consultant (not as a panelist) during the study period. All 21 experts provided consent and agreed to participate. Of the 21 experts, 20 responded to both rounds of the survey.

\section{Survey round 1}

A document containing a set of statements was circulated by email to all experts. The document had five sections and 30 statements. Panel members selected one of the following answers to each statement: strongly agree, agree, neutral, disagree, and strongly disagree.

The agreement rate was defined as the percentage of panel members who answered, "strongly agree" or "agree." The disagreement rate was defined as the percentage of panel members who answered "disagree" or "strongly disagree." Additionally, towards the end of document, there was a questionnaire regarding the optimal cutoff for an agreement rate to recommend a particular diagnostic bundle for bronchiectasis (Table 1). Panel members also had an option to write their suggestions and feedback in free text form in the document.

\section{Survey round 2}

A document for the round 2 survey was composed based on the results of the round 1 survey and feedback from the experts. This survey was emailed to all panel members who responded during round 1 . In round 2 , the experts used the same voting method as described for round 1 . The document for round 2 also indicated the rates of expert panel's agreement/disagreement. Based on the results of round 2, a third survey or an online meeting was considered if indicated. The final version of the round 2 survey is shown in Table 2.

\section{Analysis}

The panel's opinions on a diagnostic bundle for bronchiectasis were collected from the round 1 and round 2 Delphi method surveys. Based on the panel's recommendation, a $70 \% / 30 \%$ cutoff was used to decide whether or not to recommend the statement. The statement was recommended if there was $\geq 70 \%$ agreement. If the agreement was $\geq 30 \%$ but $<70 \%$, it was considered conditional based on the choice of the physician and patient. If the agreement was $<30 \%$ with a statement it was not recommended. 


\section{Results}

The first survey was circulated by email between March 24, 2021 and April 15, 2021. The response rate was 95\% $(n=20 / 21)$. In the overview section, most experts agreed on the necessity for a diagnostic bundle for bronchiectasis. Although there were differences of opinion regarding the need to test for immunodeficiency, most experts agreed on the need for additional testing of younger ( $<50$ years) patients with bronchiectasis without a definite cause and on referral to other institutions with access to diagnostic testing when cystic fibrosis (involving predominantly upper lung lobes, gastrointestinal symptoms due to malabsorption, pancreatitis, diabetes mellitus, and infertility), primary ciliary dyskinesia (predominantly middle and lower lung lobes, sinusitis, recurrent otitis media, situs inversus, and infertility), and alpha- 1 antitrypsin deficiency (panacinar emphysema in lower lung lobes) were suspected ${ }^{14,15}$. In the pulmonary function testing and microbiologic testing sections, most experts agreed on pre- and postbronchodilator spirometry, Gram stain and bacterial culture, and acid-fast bacilli stain and culture. However, there were differences of opinion regarding other pulmonary function and microbiological tests. Most panelists agreed on the need for laboratory tests for stable patients as well as paranasal sinus $\mathrm{X}$-rays when bronchiectasis was diagnosed. The specific rates of agreement and disagreement based on the round 1 survey are noted in Table 1.

The second survey was also circulated by email between May 7, 2021 and May 13, 2021. The document was sent to the 20 experts who responded to the round 1 survey. The round 2 survey had a $100 \%$ response rate. The round 2 survey attempted to narrow the discrepancies found in the round 1 survey.
Q1 Diagnostic bundle is useful Q2 Additional tests are essential in patients $(<50)$ without definite cause Q3 Chest CT

Q4 Tests for eosinophilic endotype Q5 ABPA tests in all patients Q6 ABPA tests in asthma patients Q7 Serum Ig in all patients $(<50)$ Q8 Serum lg only in suspected immunodeficiency Q9 Baseline Ab to S. pneumoniae in all patients Q10 Baseline Ab to S. pneumoniae only in suspected immunodeficiency Q11 Follow-up $\mathrm{Ab}$ to $\mathrm{S}$. pneumoniae only in suspected immunodeficiency Q12 Autoimmune markers in all patients $(<50)$ Q13 Autoimmune markers only in suspected rheumatologic disease Q14 Refer suspected PCD

Q15 Questionnaire of high sensitivity in suspected $\mathrm{PCD}$

Q16 Refer suspected A1AD

Q17 A1AD tests in panacinar emphysema without definite cause Q18 Refer suspected CF

Q19 Pre-bronchodilator spirometry

Q20 Post-bronchodilator spirometry

Q21 Diffusion capacity

Q22 Lung volume measurement

Q23 Gram stain and culture

Q24 AFB stain and culture

Q25 Fungal culture in all patients

Q26 CPA tests in all patients

Q27 CPA tests only when suspected

Q28 CBC and blood chemistry

Q29 PNS X-ray in all patients

Q30 PNS CT in all patients

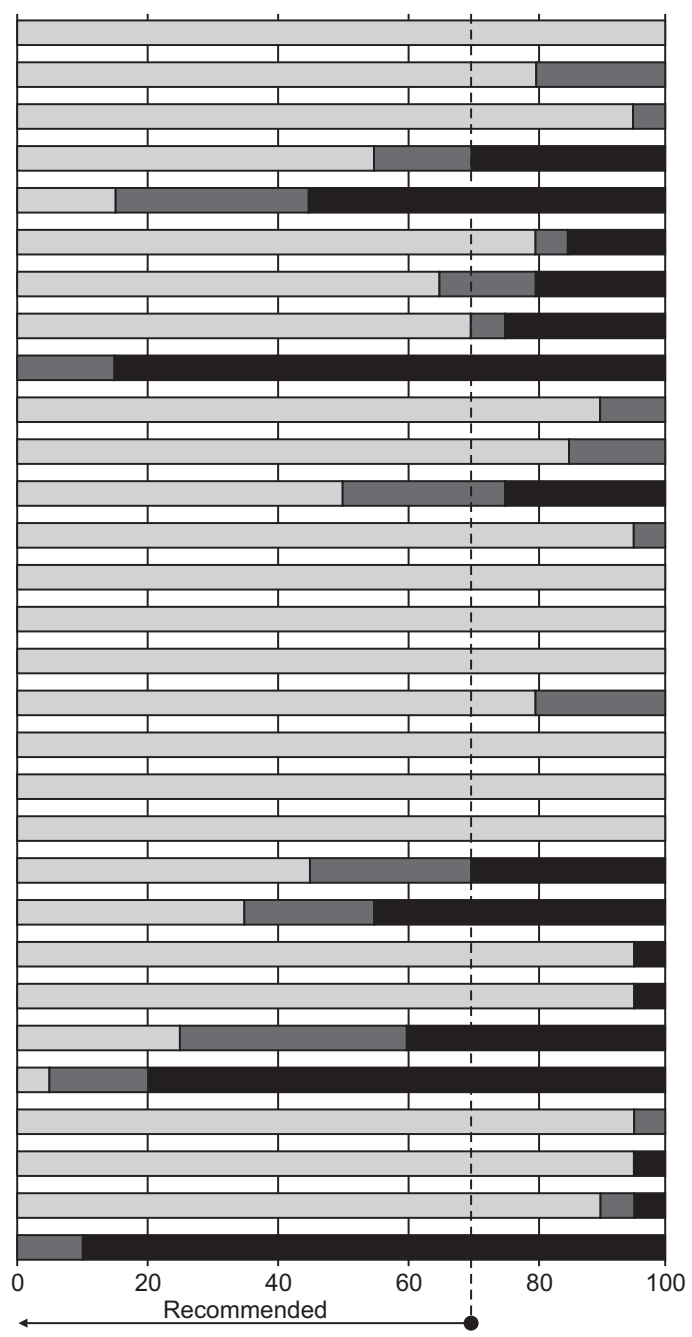

Cut-off ( $70 \%$ of agreement rate)
Figure 2. Results of survey round 2. $<50$ : $<50$ years of age; $\mathrm{CT}$ : computed tomography; ABPA: allergic bronchopulmonary aspergillosis; Ab: antibody; PCD: primary ciliary dyskinesia; A1AD: alpha-1 antitrypsin deficiency; CF: cystic fibrosis; AFB: acid-fast bacilli; CPA: chronic pulmonary aspergillosis; CBC: complete blood count; PNS: paranasal sinus. 
Table 3. Recommended diagnostic bundle for bronchiectasis in South Korea

\begin{tabular}{|c|c|}
\hline \multicolumn{2}{|r|}{ Statements } \\
\hline \multicolumn{2}{|c|}{ Recommended } \\
\hline 1 & A standardized diagnostic bundle for bronchiectasis is useful in clinical practice. \\
\hline 2 & $\begin{array}{l}\text { In patients }<50 \text { years of age without a definitive cause of bronchiectasis, additional tests should be performed to elucidate the } \\
\text { etiology beyond a standardized diagnostic bundle. }\end{array}$ \\
\hline 3 & All patients should receive a chest CT when first diagnosed with bronchiectasis. \\
\hline 4 & Tests related to ABPA should be performed only in patients with bronchiectasis and a history of asthma. \\
\hline 5 & Serum Ig levels should be measured when immunodeficiency is suspected. \\
\hline 6 & $\begin{array}{l}\text { A baseline level of specific antibody to Streptococcus pneumoniae capsular polysaccharides should be measured when } \\
\text { immunodeficiency is suspected. }\end{array}$ \\
\hline 7 & $\begin{array}{l}\text { Repetitive measurement of antibody levels specific to } S \text {. pneumoniae capsular polysaccharides should be performed } 4-8 \text { weeks } \\
\text { after pneumococcal } 23 \text { polyvalent vaccine injection when immunodeficiency is suspected and the baseline level was low. }\end{array}$ \\
\hline 8 & Autoimmune markers should be measured only when rheumatologic diseases are suspected. \\
\hline 9 & When primary ciliary dyskinesia is suspected, clinicians should refer patients to institutions where diagnostic tests are available. \\
\hline 10 & $\begin{array}{l}\text { In patients }<50 \text { years of age without a definitive cause of bronchiectasis, questionnaires with a high diagnostic sensitivity should be } \\
\text { used for the differential diagnosis of primary ciliary dyskinesia. }\end{array}$ \\
\hline 11 & $\begin{array}{l}\text { When alpha-1 antitrypsin deficiency is suspected, clinicians should refer patients to institutions where diagnostic tests are } \\
\text { available. }\end{array}$ \\
\hline 12 & $\begin{array}{l}\text { Tests for alpha-1 antitrypsin deficiency should be performed in patients }<50 \text { years of age without a definite cause of bronchiectasis } \\
\text { and demonstrate panacinar emphysema on basal lung CXR. }\end{array}$ \\
\hline 13 & When cystic fibrosis is suspected, clinicians should refer patients to institutions where diagnostic tests are available. \\
\hline 14 & Prebronchodilator spirometry should be performed in all patients when first diagnosed with bronchiectasis. \\
\hline 15 & Postbronchodilator spirometry is indicated for all patients when first diagnosed with bronchiectasis. \\
\hline 16 & Sputum Gram stain and bacterial culture are indicated for all patients when first diagnosed with bronchiectasis. \\
\hline 17 & Sputum AFB stain and culture should be performed in all patients when first diagnosed with bronchiectasis. \\
\hline 18 & Tests for chronic pulmonary aspergillosis should be performed only when chronic pulmonary aspergillosis is suspected. \\
\hline 19 & $\begin{array}{l}\text { All patients should receive laboratory testing, including CBC, liver function tests, BUN, creatinine, and CRP when they are in a } \\
\text { stable state. }\end{array}$ \\
\hline 20 & All patients should receive a PNS X-ray when first diagnosed with bronchiectasis. \\
\hline \multicolumn{2}{|c|}{ Conditional } \\
\hline 1 & All patients receive tests to evaluate eosinophilic endotype (CBC, total IgE) when first diagnosed with bronchiectasis. \\
\hline 2 & Serum Ig levels are measured in patients $<50$ years of age when first diagnosed with bronchiectasis. \\
\hline 3 & Autoimmune markers are measured in patients $<50$ years of age when first diagnosed with bronchiectasis. \\
\hline 4 & Diffusion capacity is included in the diagnostic bundle for bronchiectasis. \\
\hline 5 & Lung volume is included in the diagnostic bundle for bronchiectasis. \\
\hline \multicolumn{2}{|c|}{ Not recommended } \\
\hline 1 & None of the patients should undergo testing for ABPA when first diagnosed with bronchiectasis. \\
\hline 2 & $\begin{array}{l}\text { A baseline level of antibody specific to } S \text {. pneumoniae capsular polysaccharides should not be measured in any patient first } \\
\text { diagnosed with bronchiectasis. }\end{array}$ \\
\hline 3 & A sputum fungal culture should not be performed in any patient first diagnosed with bronchiectasis. \\
\hline 4 & None of the patients should undergo testing for chronic pulmonary aspergillosis when first diagnosed with bronchiectasis. \\
\hline 5 & one of the patients should receive a PNS CT when first diagnosed with bronchiectasis. \\
\hline
\end{tabular}

If age (e.g., less than 50 years) is not specified, the statements are applicable to adults of all ages.

CT: computed tomography; ABPA: allergic bronchopulmonary aspergillosis; CXR: chest X-ray; AFB: acid-fast bacilli; CBC: complete blood count; BUN: blood urea nitrogen; CRP: C-reactive protein; PNS: paranasal sinus. 
Expert panelists did not recommend testing for allergic bronchopulmonary aspergillosis (ABPA), immunodeficiency, autoimmune diseases, and chronic pulmonary aspergillosis in all patients with bronchiectasis. Instead, they recommended such tests only when the diseases were clinically suspected as follows: (1) ABPA in patients with uncontrolled asthma and recurrent pulmonary opacities, (2) immunodeficiency in patients with a history of recurrent infection or comorbidities of hematological malignancies, (3) autoimmune diseases in patients with known connective tissue diseases (especially rheumatoid arthritis) or suspected symptoms of connective tissue diseases, and (4) chronic pulmonary aspergillosis in patients with a long-term (several months) history of chronic productive cough (or hemoptysis) and one or more cavities on chest $X$-rays ${ }^{14,15,21}$. Detailed rates of agreement and disagreement from the round 2 survey are noted in Table 2 and Figure 2.

Table 3 summarizes the results of the modified Delphi survey regarding a diagnostic bundle for bronchiectasis in South Korea. All 30 statements are classified into three categories as recommended, conditional, or not recommended. There were 20 recommendations, including when to order specific tests to determine etiology, when to refer patients to more specialized centers, and specific microbiological, laboratory, radiological, and pulmonary function tests. Additionally, five statements were conditionally recommended and five not recommended.

\section{Discussion}

In this study involving 21 expert participants, 30 statements regarding a diagnostic bundle for bronchiectasis were classified as recommended, conditional, or not recommended. An expert panel agreed that (1) a standardized diagnostic bundle is useful in clinical practice; (2) diagnostic tests for specific diseases, including immunodeficiency, ABPA, and rheumatologic diseases should be performed when clinically suspected; (3) initial diagnostic tests, including sputum microbiology, complete blood count, blood chemistry, chest computed tomography, paranasal X-ray, and spirometry are essential for all patients with bronchiectasis; and (4) patients suspected with rare causes such as primary ciliary dyskinesia, cystic fibrosis, and alpha- 1 antitrypsin deficiency should be referred to specialized centers.

As previously noted in the international guideline ${ }^{15}$, this study also found that all experts agreed that a standardized diagnostic bundle for bronchiectasis is useful in clinical practice. In line with this recommendation, a previous study noted that a standardized etiological algorithm for bronchiectasis has reduced the frequency of diagnosis of idiopathic bronchiectasis from $42 \%$ to $29 \%^{22}$. Given the substantial differences in the etiology of bronchiectasis and clinical presentation among different regions and ethnic groups ${ }^{10}$, the development of a diagnostic bundle for bronchiectasis optimized for the population in South Korea is necessary. This expert consensus will be the cornerstone for the future development of the Korean bronchiectasis guideline, incorporating the study results from the Korean Multicentre Bronchiectasis Audit and Research Collaboration (KMBARC) ${ }^{23}$.

In this study, the experts recommended diagnostic tests that are currently incorporated in international bronchiectasis guidelines released recently ${ }^{14,15}$. Identification of nontuberculous mycobacteria, commonly isolated in patients with bronchiectasis ${ }^{24}$, plays a role in diagnosing treatable etiologies and improving long-term outcomes ${ }^{25}$. Diagnosing chronic infections with Pseudomonas or other bacteria may also explain why some patients experience severe disease and exacerbations more frequently ${ }^{25,26}$. This microbiological information can assist clinicians in diminishing symptom burden and future risk of exacerbation ${ }^{27,28}$. Similarly, pulmonary function tests, recommended by most experts in this study, have been used to estimate the mortality of patients with bronchiectasis ${ }^{29}$ and identify patients might benefit from bronchodilators ${ }^{27,28,30}$.

Interestingly, there were some discrepancies between the study panel's recommendations and international guidelines. Tests for ABPA were not recommended for all patients with bronchiectasis but only in those with a history of asthma. However, tests for ABPA are included in a minimum diagnostic bundle of the European Respiratory Society and the British Thoracic Society guidelines ${ }^{14,15}$. Additionally, although the British Thoracic Society guideline recommends testing for immunoglobulins and specific antibodies to Streptococcus pneumoniae capsular polysaccharides in all patients with bronchiectasis ${ }^{14}$, the current panel recommended testing only in specific subpopulations. These discrepancies may reflect the Korean clinicians frequently encounter post-infectious, including post-tuberculosis (TB), bronchiectasis as a major portion of bronchiectasis in real-world practice. Additionally, this could also be attributed to limited testing of specific antibodies to $S$. pneumoniae capsular polysaccharides in South Korea and the relatively low level of awareness regarding primary immunodeficiency among physicians. According to the KMBARC registry data, the most common etiologies of bronchiectasis were idiopathic (41\%), TB (20\%), post-infective $(20 \%)$, asthma (5\%), and nontuberculous mycobacteria (4\%) in South Korea ${ }^{10}$. However, the decrease in TB incidence over the past decades in South Korea ${ }^{31}$ will likely change the major etiologies of bronchiectasis in the future. Additionally, developing a diagnostic bundle to evaluate the etiology of bronchiectasis systematically may decrease the rate of idiopathic disease resulting in changes in major etiologies in South Korea, suggesting the need for further reviews of the Korean bronchiectasis registry. The diagnostic bundle may need to be updated according to the study results.

There are potential limitations to this study. First, because most experts are respiratory physicians working at secondary 
or tertiary university-affiliated hospitals, all of the diagnostic tests recommended by this study may not be available in primary care settings. Second, this study focused on the development of a diagnostic bundle for adult patients with bronchiectasis. Therefore, a further study is needed to develop a diagnostic bundle for pediatric patients with bronchiectasis. In contrast, two pediatricians, participating in this study, are experts in the field of primary ciliary dyskinesia and immunodeficiency respectively, which is a strength of this study.

In conclusion, in this Delphi survey, expert consensus statements on specific diagnostic tests were proposed to determine the etiology and appropriate laboratory, microbiological, and pulmonary function tests for managing patients with bronchiectasis in South Korea.

\section{*Author Affiliations}

${ }^{1}$ Division of Pulmonary, Allergy, and Critical Care Medicine, Department of Internal Medicine, Hallym University Kangnam Sacred Heart Hospital, Hallym University College of Medicine, Seoul, ${ }^{2}$ Division of Pulmonary Medicine and Allergy, Department of Internal Medicine, Hanyang University College of Medicine, Seoul, ${ }^{3}$ Division of Pulmonary Medicine, Department of Internal Medicine, Ulsan University Hospital, University of Ulsan College of Medicine, Ulsan, ${ }^{4}$ Division of Pulmonology and Allergy, Department of Internal Medicine, College of Medicine, Yeungnam University and Regional Center for Respiratory Diseases, Yeungnam University Medical Center, Daegu, ${ }^{5}$ Department of Internal Medicine, Yonsei University Wonju College of Medicine, Wonju, ${ }^{6}$ Division of Pulmonary and Critical Care Medicine, Department of Medicine, Samsung Medical Center, Sungkyunkwan University School of Medicine, Seoul, ${ }^{7}$ Division of Pulmonary and Critical Care Medicine, Department of Internal Medicine, Severance Hospital, Yonsei University College of Medicine, Seoul, ${ }^{8}$ Department of Internal Medicine, Gyeongsang National University School of Medicine and Gyeongsang National University Hospital, Jinju, ${ }^{9}$ Department of Pulmonary and Critical Care Medicine, Asan Medical Center, University of Ulsan College of Medicine, Seoul, ${ }^{10}$ Division of Pulmonary and Critical Care Medicine, Department of Internal Medicine, Seoul St. Mary's Hospital, College of Medicine, The Catholic University of Korea, Seoul, ${ }^{11}$ Department of Internal Medicine, Jeju National University Hospital, Jeju National University School of Medicine, Jeju, ${ }^{12}$ Division of Pulmonary, Allergy and Critical Care Medicine, Department of Internal Medicine, Korea University Guro Hospital, Korea University College of Medicine, Seoul, ${ }^{13}$ Department of Internal Medicine, Chonnam National University Medical School, Chonnam National University Hospital, Gwangju, ${ }^{14}$ Department of Internal Medicine, SMGSNU Borame Medical Center, Seoul National University College of Medicine, Seoul, ${ }^{15}$ Division of Pulmonary and Critical
Care Medicine, Department of Internal Medicine, Ewha Womans University College of Medicine, Seoul, ${ }^{16}$ Division of Pulmonary, Allergy and Critical Care Medicine, Department of Internal Medicine, Hallym University Kangdong Sacred Heart Hospital, Seoul, ${ }^{17}$ Department of Pediatrics, Chungnam National University College of Medicine, Daejeon, ${ }^{18}$ Department of Pediatrics, Samsung Medical Center, Sungkyunkwan University School of Medicine, Seoul, ${ }^{19}$ Division of Pulmonary, Allergy and Critical Care Medicine, Department of Internal Medicine, Konkuk University School of Medicine, Seoul, Republic of Korea

\section{Authors' Contributions}

Conceptualization: Choi H, Lee H, Ra SW, Oh YM. Methodology: Choi H, Lee H, Ra SW, Jang JG, Lee JH, Jhun BW, Park HY, Jung JY, Oh YM. Formal analysis: Choi H, Lee SJ, Jo KW, Rhee CK, Kim C, Lee SW, Oh YM. Data curation: Choi H, Min KH, Kwon YS, Kim DK, Lee JH. Investigation: Choi H, Lee H, Ra SW, Park YB, Chung EH, Kim YJ, Yoo KH, Oh YM. Writing - original draft preparation: Choi H, Oh YM. Writing - review and editing: all authors. Approval of final manuscript: all authors.

\section{Conflicts of Interest}

No potential conflict of interest relevant to this article was reported.

\section{Acknowledgments}

We would like to thank Sang Yong Sim, RN (Clinical Research Center for Chronic Obstructive Airway Diseases, Asan Medical Center) for assistance with the study.

\section{Funding}

No funding to declare.

\section{References}

1. Choi H, Yang B, Nam H, Kyoung DS, Sim YS, Park HY, et al. Population-based prevalence of bronchiectasis and associated comorbidities in South Korea. Eur Respir J 2019;54:1900194.

2. Kim C, Kim DG. Bronchiectasis. Tuberc Respir Dis 2012;73: 249-57.

3. Seitz AE, Olivier KN, Adjemian J, Holland SM, Prevots DR. 
Trends in bronchiectasis among medicare beneficiaries in the United States, 2000 to 2007. Chest 2012;142:432-9.

4. Ringshausen FC, de Roux A, Pletz MW, Hamalainen N, Welte $\mathrm{T}$, Rademacher J. Bronchiectasis-associated hospitalizations in Germany, 2005-2011: a population-based study of disease burden and trends. PLoS One 2013;8:e71109.

5. Ringshausen FC, de Roux A, Diel R, Hohmann D, Welte T, Rademacher J. Bronchiectasis in Germany: a populationbased estimation of disease prevalence. Eur Respir J 2015;46:1805-7.

6. Quint JK, Millett ER, Joshi M, Navaratnam V, Thomas SL, Hurst JR, et al. Changes in the incidence, prevalence and mortality of bronchiectasis in the UK from 2004 to 2013: a population-based cohort study. Eur Respir J 2016;47:186-93.

7. Yang B, Choi H, Lim JH, Park HY, Kang D, Cho J, et al. The disease burden of bronchiectasis in comparison with chronic obstructive pulmonary disease: a national database study in Korea. Ann Transl Med 2019;7:770.

8. Choi H, Yang B, Kim YJ, Sin S, Jo YS, Kim Y, et al. Increased mortality in patients with non cystic fibrosis bronchiectasis with respiratory comorbidities. Sci Rep 2021;11:7126.

9. Sin S, Yun SY, Kim JM, Park CM, Cho J, Choi SM, et al. Mortality risk and causes of death in patients with non-cystic fibrosis bronchiectasis. Respir Res 2019;20:271.

10. Lee H, Choi H, Chalmers JD, Dhar R, Nguyen TQ, Visser SK, et al. Characteristics of bronchiectasis in Korea: first data from the Korean Multicentre Bronchiectasis Audit and Research Collaboration registry and comparison with other international registries. Respirology 2021;26:619-21.

11. Dhar R, Singh S, Talwar D, Mohan M, Tripathi SK, Swarnakar $\mathrm{R}$, et al. Bronchiectasis in India: results from the European Multicentre Bronchiectasis Audit and Research Collaboration (EMBARC) and Respiratory Research Network of India Registry. Lancet Glob Health 2019;7:e1269-79.

12. McShane PJ, Naureckas ET, Tino G, Strek ME. Noncystic fibrosis bronchiectasis. Am J Respir Crit Care Med 2013;188:647-56.

13. McDonnell MJ, Aliberti S, Goeminne PC, Restrepo MI, Finch S, Pesci A, et al. Comorbidities and the risk of mortality in patients with bronchiectasis: an international multicentre cohort study. Lancet Respir Med 2016;4:969-79.

14. Hill AT, Sullivan AL, Chalmers JD, De Soyza A, Elborn SJ, Floto AR, et al. British Thoracic Society Guideline for bronchiectasis in adults. Thorax 2019;74:1-69.

15. Polverino E, Goeminne PC, McDonnell MJ, Aliberti S, Marshall SE, Loebinger MR, et al. European Respiratory Society guidelines for the management of adult bronchiectasis. Eur Respir J 2017;50:1700629.

16. Gao YH, Guan WJ, Liu SX, Wang L, Cui JJ, Chen RC, et al. Aetiology of bronchiectasis in adults: a systematic literature review. Respirology 2016;21:1376-83.
17. Amati F, Simonetta E, Pilocane T, Gramegna A, Goeminne P, Oriano M, et al. Diagnosis and initial investigation of bronchiectasis. Semin Respir Crit Care Med 2021;42:513-24.

18. Dalkey N, Helmer O. An experimental application of the Delphi method to the use of experts. Manag Sci 1963;9:458-67.

19. Vakil N, van Zanten SV, Kahrilas P, Dent J, Jones R, Global Consensus G. The Montreal definition and classification of gastroesophageal reflux disease: a global evidence-based consensus. Am J Gastroenterol 2006;101:1900-20.

20. Bennett C, Vakil N, Bergman J, Harrison R, Odze R, Vieth M, et al. Consensus statements for management of Barrett's dysplasia and early-stage esophageal adenocarcinoma, based on a Delphi process. Gastroenterology 2012;143:336-46.

21. Denning DW, Cadranel J, Beigelman-Aubry C, Ader F, Chakrabarti A, Blot S, et al. Chronic pulmonary aspergillosis: rationale and clinical guidelines for diagnosis and management. Eur Respir J 2016;47:45-68.

22. Araujo D, Shteinberg M, Aliberti S, Goeminne PC, Hill AT, Fardon T, et al. Standardised classification of the aetiology of bronchiectasis using an objective algorithm. Eur Respir J 2017;50:1701289.

23. Lee H, Choi H, Sim YS, Park S, Kim WJ, Yoo KH, et al. KMBARC registry: protocol for a multicentre observational cohort study on non-cystic fibrosis bronchiectasis in Korea. BMJ Open 2020;10:e034090.

24. Yang B, Ryu J, Kim T, Jo YS, Kim Y, Park HY, et al. Impact of bronchiectasis on incident nontuberculous mcobacterial pulmonary disease: a 10-year national cohort study. Chest 2021;159:1807-11.

25. Jose RJ, Loebinger MR. Clinical and radiological phenotypes and endotypes. Semin Respir Crit Care Med 2021;42:549-55.

26. Aliberti S, Lonni S, Dore S, McDonnell MJ, Goeminne PC, Dimakou K, et al. Clinical phenotypes in adult patients with bronchiectasis. Eur Respir J 2016;47:1113-22.

27. Lee H, Oh YM. Clinical approach to non-cystic fibrosis bronchiectasis based on recent clinical guideline. Korean J Med 2020;95:141-50.

28. Choi H, Lee H, Ra SW, Oh YM. Update on pharmacotherapy for adult bronchiectasis. J Korean Med Assoc 2020;63:486-92.

29. Chalmers JD, Goeminne P, Aliberti S, McDonnell MJ, Lonni S, Davidson J, et al. The bronchiectasis severity index: an international derivation and validation study. Am J Respir Crit Care Med 2014;189:576-85.

30. Lee SY, Lee JS, Lee SW, Oh YM. Effects of treatment with longacting muscarinic antagonists (LAMA) and long-acting betaagonists (LABA) on lung function improvement in patients with bronchiectasis: an observational study. J Thorac Dis 2021;13:169-77.

31. Kim JH, Yim JJ. Achievements in and challenges of tuberculosis control in South Korea. Emerg Infect Dis 2015;21:1913-20. 